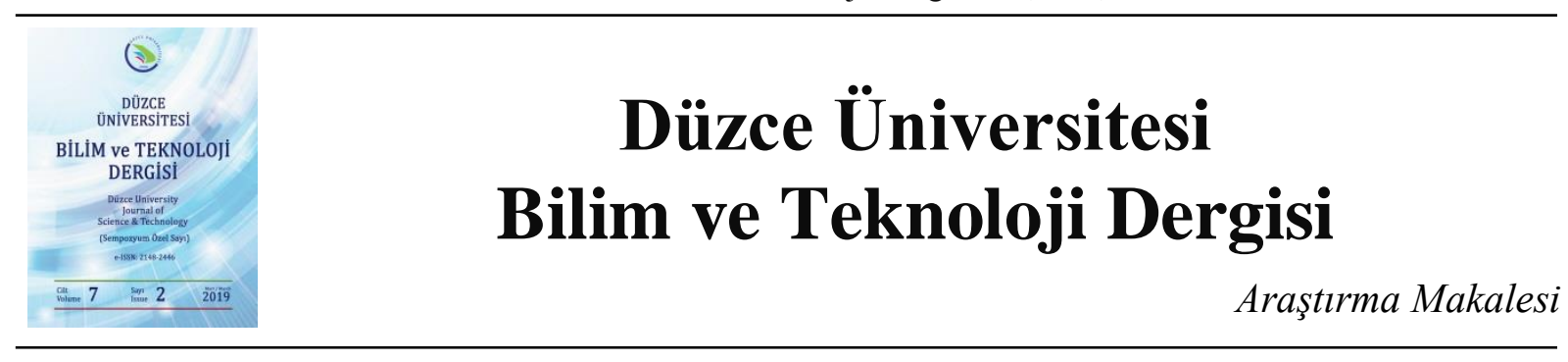

\title{
Üç Boyutlu (3B) Baskı Teknolojisinin Eğitimde Uygulanabilirliği: Senirkent MYO Örneği
}

\author{
Koray ÖZSOY ${ }^{\mathrm{a}, *}$ \\ ${ }^{a}$ Elektrik ve Enerji Bölümü, Senirkent MYO, Süleyman Demirel Üniversitesi, Isparta, TÜRKIYE \\ - Sorumlu yazarin e-posta adresi: korayozsoy@sdu.edu.tr
}

\begin{abstract}
ÖZET
Meslek yüksekokulunun amacı, mesleki ve teknik eğitimde bilim ve teknolojik alanda gelişmelere uyum sağlayabilecek, endüstrinin ihtiyaç duyduğu nitelikli, kaliteli ara kademe insan gücünü yetiştirmektir. Çalışma bu amaca yönelik Senirkent Meslek Yüksekokulu kapsamında 3 boyutlu (3B) bask1 teknolojisinin eğitimde uygulanabilirliği test etmeyi hedeflemektedir. Bu hedefe bağlı olarak, 3B bask1 teknolojisi ile jet motoru, otomotiv diferansiyeli ve robot kol prototip tasarımı ve imalatı gerçekleştirilmiştir. Bunun yanı sıra çalışma kapsamında nitel araştırma desenlerinden fenomenolojik desen tasarlanmıştır. Katılımcılar amaçsal örnekleme yöntemlerinden ölçüt örnekleme yöntemiyle seçilmiş, bu doğrultuda ön lisans programında öğrenim gören son sınıf 6 kişi ile yarı - yapılandırılmış görüşme tekniği kullanılarak veriler toplanmıştır. Elde edilen bulgular; iki ayrı tema halinde kategorize edilmiştir. Gerçekleştirilen çalışma neticesinde öğrencilerin, 3B baskı teknolojisinin eğitimde uygulanabilirliği ile 3B düşünebilme kabiliyetin elde edilmesi sağlanmıştır. Ayrıca öğrencilerin, analitik düşünme ile zihinsel, mesleki ve toplumsal gelişimlerine olumlu katkı sağladığı görülmüştür. Sanayiye nitelikli teknik eleman yetiştiren meslek yüksekokullarında 3B baskı teknolojisi yenilikçi eğitim uygulamalarının, ülkemizin "Dijital Dönüşüm” devrimini gerçekleştirmesine olumlu katkı sağlayacağı düşünülmektedir.
\end{abstract}

Anahtar Kelimeler: : 3B baskl, eğitim, endüstri devrimi

\section{Usability of Three Dimensional (3D) Printing Technologies in Education: Senirkent MYO Case}

\begin{abstract}
The scope of the vocational school is to train the man power of high quality intermediate member which the business life needs to adapt to the scientific and technological development in vocational and technical education. This study is to test the applicability of Three Dimensional (3D) printing technology in education within the scope of Senirkent Vocational School for this purpose. Depending on this target, jet engine, automotive differential and robot arm prototip design and manufacturing have been performed with 3D printer technology. In addition, it was designed as a phenomenological patterns of the qualitative research designs in this study. Participants are selected by sampling criteria method, a type of purposeful sampling methods. Data
\end{abstract}


was collected with the method of semi-structured interviews with 6 students. Findings; categorized into two distinct themes. As a result of the study carried out, 3D printing technology has been applied in education and the students' 3D thinking ability is achieved. The application provides students with 3D thinking ability. It has also been seen to contribute to the physical, mental, vocational and social development of the students. The training and using of 3D printing Technology by application innovative education in vocational schools which produce industrial technical personnel is thought to promote to the realization of the "Digital Transformation" revolution of our country.

Keywords: 3D printing, education, industrial revolution

\section{GiRIȘ}

B ir toplum, ancak o toplumu oluşturan bireylerin ortalaması kadar mükemmel olabilir. Bireysel veya toplumsal mükemmelliğin aracı eğitimdir [1]. Ülkemizin bilim ve teknoloji alanında rekabete etkili, sistemli ve kurumsal bir kimlikle katılması, hızla gelişen ve değişen dünyada muasır medeniyetler seviyesini aşması gerekmektedir. Bunun için mesleki ve teknik eğitime ağırlık ve öncelik verilmeli, , okullaşma oranlarını ve eğitim standartlarını ileri ülkeler seviyesine çıkmalıdır. [2]. Teknik bilimlerin doğuşu insanoğlunun bir şeyler icat ettiği günlere kadar dayanır. Bu bilim dallarından, matematik ve fen bilimleri ve bunların uygulanması elbette ki mühendis ve teknikerlerin işidir. Teorik bilgiler, bunlara dayalı hesapların yapılması ve projeler mühendislerin işiyken, bunların uygulanması ve pratiğe dönüştürülmesi teknikerlere düşmektedir. Teknikerleri yetiştiren meslek yüksekokulları, staj konusundan uygulama ve iş yeri eğitimine, eğitim kalitesine, mezunların istihdamına ve meslek yüksekokullarının algı ve imaj sorunlarına kadar pek çok problemle karşı karşıyadır [3].

Endüstri 4.0 sürecinde lokomotif görevi gören şüphesiz mesleki eğitim veren liseler, meslek yüksekokulları, mühendislik fakülteleridir. Dünyadaki toplumsal, ekonomik ve kültürel değişimlere yol açan Endüstri Devrimleri, belli aşamalarla, uzun sürelerde gerçekleşmiştir. $\mathrm{Bu}$ bakımdan geçmişten günümüze kadar olan dönemlerde, birbirinden farklı etkilere sahip 3 farklı Endüstri Devrimi'nden söz etmek mümkündür. Türkiye'nin ilk üç endüstri devrimini kaçırdığını, 4'üncü endüstri devrimini 1skalamaması gerektiği dile getirilmektedir. Endüstri 4.0 ile gelen yeni üretim biçiminde 3B baskı teknolojisinden nesnelerin internetine (Internet of Things-IOT) birçok teknoloji üretiminde söz sahibi olacağı öngörülmektedir.

$\mathrm{Bu}$ çalışma ile 3B baskı teknolojilerinin eğitimindeki fen, sağlık ve sosyal bilimler alanlarında kullanılabileceği, bunun sonucunda öğrencilerin daha becerili, teknik ve donanımlı hale gelerek ülkenin gelecek sanayi strateji hedeflerine ulaşmasında olumlu etkisi olacağ görülmüştür. Çalışma bu amaca yönelik Senirkent Meslek Yüksekokulu kapsamında 3B bask1 teknolojisinin eğitimde uygulanabilirliği test etmeyi hedeflemektedir. Bu hedefe bağlı olarak, 3B baskı teknolojisi ile jet motoru, otomotiv diferansiyeli ve robot kol prototip tasarımı ve imalatı gerçekleştirilmiştir. Bu amaçla 3B bask1 teknolojileri ile otomotiv diferansiyeli, robot kol ve jet motor tasarım ve imalat gerçekleştirilmiştir.

Uygulama ile öğrencilerin 3B düşünebilme kabiliyetin elde edilmesi sağlanmıştır. Ayrıca öğrencilerin zihinsel, mesleki ve toplumsal gelişimlerine olumlu katkı sağladığı görülmüştür. Sanayiye nitelikli 
teknik eleman yetiştiren meslek yüksekokullarında 3B baskı teknolojisi yenilikçi eğitim uygulamaları verilmesi ve kullanılması ülkemizin "Dijital Dönüşüm” devrimini gerçekleştirmesine olumlu katkı sağlayacağı düşünülmektedir.

Bu çalışmanın amacı, Süleyman Demirel Üniversitesi Senirkent Meslek Yüksekokulu'nda bulunan teknik programda okuyan öğrencilerinin 3B baskı teknolojileri hakkında bilgilendirme ve kullanma durumunu incelemektir. Bu temel amaç doğrultusunda aşağıdaki sorulara cevap aranmıştır:

1) Öğrencilerin 3B bask1 teknolojisi ile üç boyutlu düşünebilme kavramına ilişkin bilişsel yapıları nasıl şekillenmektedir?

2) Öğrencilerin 3B baskı teknolojisinin eğitim alanında kullanımına yönelik gerçekleştiren uygulamalarda genel eğilimler ne yöndedir?

\section{II. ÜÇC BoyUtLu (3B) BASKI TEKNOLOJISI (EKLEMELİ İMALAT)}

Eklemeli imalat, alışılmamış imalat yöntemlerinden birisidir. Yöntemin temeli, birbiri üzerine kat kat malzeme eklemeye dayanmaktadır. Bu yöntemdeki amaç; geometrik karışıklığı sebebiyle geleneksel imalat yöntemleri ile imalatı mümkün olmayan parçaları imal ederek, imal edilebilirlik kısıtını ortadan kaldırmaktır. Son zamanlardaki literatür kaynaklarında da bu konu ile ilgili çalışmalara önem verildiği görülmektedir [4-6]. Eklemeli imalat yöntemleri, kullanılan ham malzeme ve katmanları birleştirme prensibine göre kendi içerisinde farklılıklar göstermekle beraber temel imalat teknikleri aynıdır. $\mathrm{Bu}$ konuda farklı imalat teknolojisi kullanarak imalat yapan birçok Eklemeli İmalat yöntemi bulunmaktadır. Bunlara örnek olarak; Üç Boyutlu Baskı (3BB), Ergiterek Yığma ile Modelleme (EYM), Lazer Işı̆̆ı ile Kürleme (LIK), Kat-kat Nesne İmalat (KNİ), Seçici Lazer Sinterleme (SLS)/Seçici Lazer Ergitme (SLE) verilebilir. Bu teknikler ile sıv1 reçineden, polimerlerden, polimer tozlarından ve metal tozlarından 3B fiziksel parçalar imal edilebilmektedir.

3B baskı teknolojisi, üç farklı birimde gerçekleştirilen aşamalara ayrılabilir. Bunlar; Bilgisayar Destekli Tasarım (BDT) ve 3B baskı imalat yazılımı, 3B baskı makinesidir. BDT yazılımında modelin çizimi ve .STL dosya formatına dönüştürme işlemleri yapılır. 3B baskı imalat yazılımda, .STL dosya onarımı, parça konumlandırma ve yerleşimi, parça imalatı için destek yapısı oluşturma, modelin dilimlenmesi, işleme parametrelerin belirlenmesi ve takım yolu oluşturmadır. 3B baskı makinesinde parça imal edilmektedir. İmalat işlemi bir modelin BDT yazılımında tasarımı ile başlar ve modelin makinada imal (inşa) edilmesi ile sonlanır. 3B baskı teknolojilerinde diğer imalat yöntemlerinde olduğu gibi planlı takım hareketleri ve özel takımlar gerektirmemektedir. İmal edilecek bir parça, BDT yazılımı ile oluşturulan 3B modelden dilimleme ile iki boyutlu (2B) geometrilere dönüştürülmekte ve katman katman inşa edilmektedir.

Eklemeli imalat teknolojilerinde metal parça imalatında en yaygın kullanılanlarından bir tanesi Seçiçi Lazer Sinterleme/Ergitme (SLS/E)'dir. Bu yöntemde 1sıtıldığında kaynaşabilen toz halindeki bir inşa hammaddesi ince ve düzgün bir tabaka halinde yayılır. Ardından yüzeydeki seçilen bölgeler lazer 1şınıyla taranır. Işının yüzeye çarptığı noktalarda oluşan sıcaklıkla toz malzeme kısmen eriyerek veya sinterlenerek temas halinde olduğu diğer toz taneleri ile kaynaşır. Bu işlemden sonra inşa zarfinın tabanında bulunan platform, bir katman kalınlığı kadar aşağı çekilir. Her katmanın inşası için bu işlemler gerektiği kadar tekrarlandıktan sonra, inşa süresince doğal bir destek görevi üstlenmiş olan serbest tozlar firça veya vakum emici ile manuel olarak temizlenerek üretilen parça alınır. 
3B yazdırma aynı zamanda "masaüstü imalat" olarakta bilinmektedir. 3B bask1 teknolojisinde nesnelerin yazdırma işlemi çok ağızlı bir püskürtme kafası ile yapıştırıcı püskürtülerek tozlar birbirine bağlanmaktadır. Daha sonra toz serme silindiri ile yeni bir katman toz yayılmaktadır. İmalat tamamlandıktan sonra, destek malzemesi görevi görmüş olan tozlar, vakum temizleyici veya firçayla temizlenir ve parça imal edilmiş olur[7,8] (Şekil 1).

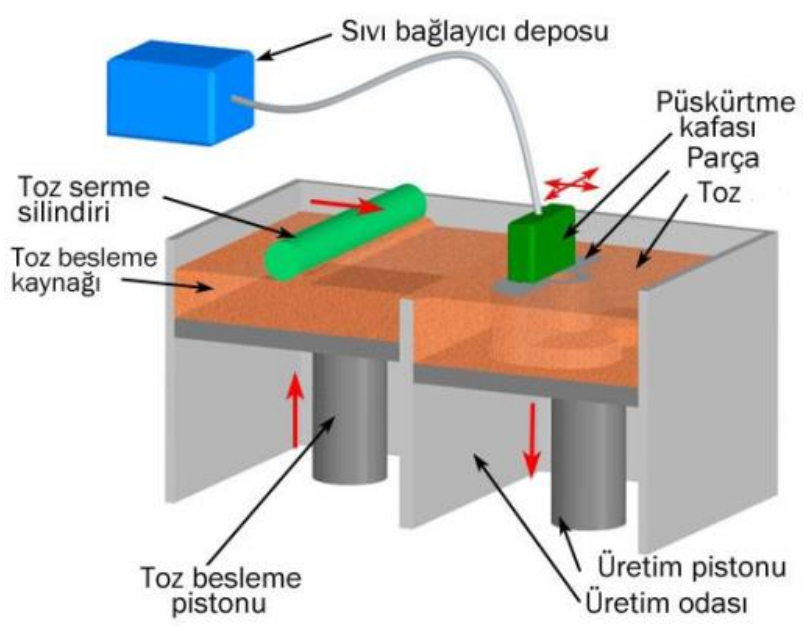

Şekil 1. 3 Boyutlu bask teknolojisinin işlem şematiği [9]

\section{3B Baski Teknolojisi İle Jet Motoru Prototip Tasarimi Ve İMALATI}

M.S. 250 yıllarında ilk defa gaz reaksiyonu ile çalışan makine Aleksandriali Heron tarafindan icat edilmiştir. Buluşun özelliği, kapalı bir küresel kapta içine gönderilen basınçlı gazın bükümlü borulardan fişkırmasıyla dönmesiyle elde edilen motordur. Barutla atılan roketler 1232 yıllarında, Moğollar ile yapılan savaşta Çinliler tarafindan silah olarak savaşta kullanılmıştır. Isaac Newton gaz tahrikiyle çalışan ilk vasıta icat etmiştir. Ayrıca Newton 1687 yılında "Hareket Miktarı Teoremi" ile jet tepkisini fiziki olarak açıklamıştır [10]. Jet motorlarını ilk defa 1791 yılında John Baber tarafından tasarlanmıştır. 1911 yılında, Alfred Büchi tarafından turbo şarjör tasarlanmış ve imal edilmiştir. 1916'da uçaklarda kullanılmaya başlanılmıştır. Whittle, difüzör ile jet motoru bir arada kullanarak jet motoru yapmıştır. Daha sonra 1930 yılında patentini almıştır. Bu turbojet motorun imalatı için 1936 yılında Power Jets Ltd. şirket kurulmuştur. "Power Jet W.1" isimli jet motoru 1941 y1lında Gloster G.49 uçağında kullanılmıştır. II. Dünya savaşında kullanılan jet motorlu uçaklar savaşın kaderini değiştirmiştir. Savaş esnasında jet motorlu "Messerschmitt Me-262" isimli Alman uçağı başarılı bir uygulama sergilemiştir[11,12].

Geçmişten günümüze kadar olan zamanda her zaman güç ve hızın simgesi olan jet motoru, havacılık tarihindeki önemli buluşlardan bir tanesi olup, tarihe yön veren bir teknolojidir. Teknolojinin temelinde etki-tepki prensibi yer almaktadır. Şekil 2'de gösterildiği gibi jet motoru hava girişi, türbin, yanma odası, nozül ve kompresörden oluşmaktadır. Jet motorları önden havayı emer ve kompresörlerde sıkıştırır. Sıkışan hava ısınır ve basıncı artar. Isınan ve basıncı artan havaya yüksek hızda yakıt püskürtülerek yanması sağlanır. Yanan yakıt-hava karışımı ise motorun çıkışına 
yönlendirilerek itme kuvveti oluşturulur. Böylece hava aracı harekete başlar. Günümüzde karmaşı geometriye sahip parçaları imal edip, imal edilebilir kısıtını ortadan kaldıran 3B baskı teknolojileri ile jet motoru imal edilmektedir.

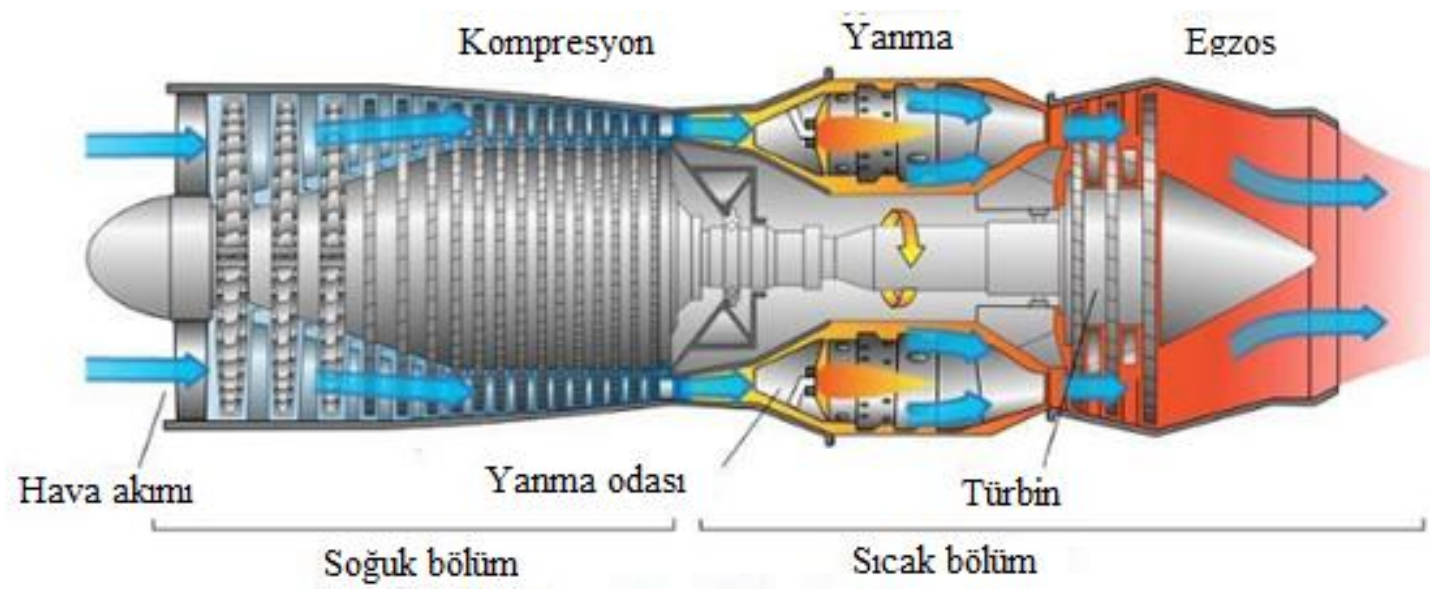

Şekil 2. Jet motorun bileşenleri [13]

Şekil 3'de gösterildiği gibi Monash Üniversitesi ile CSİRO ortaklaşa çalışması ile 3B Bask1 teknolojisiyle bir jet motoru imal ettiler. Jet motor, ilk kez 2015 yılında Avustralya Uluslararas1 Havacılık Fuarı Avalon Airshow'da sergilenmiştir. Boeing ve Airbus firmaları fuarda ilgi çeken bu jet motorunu detaylı incelemiştir. İmal edilen Jet motorun özellikleri şöyledir: kısa zamanda imalat, yakıt az kullanması ve hafifletilmiş olmasıdır.

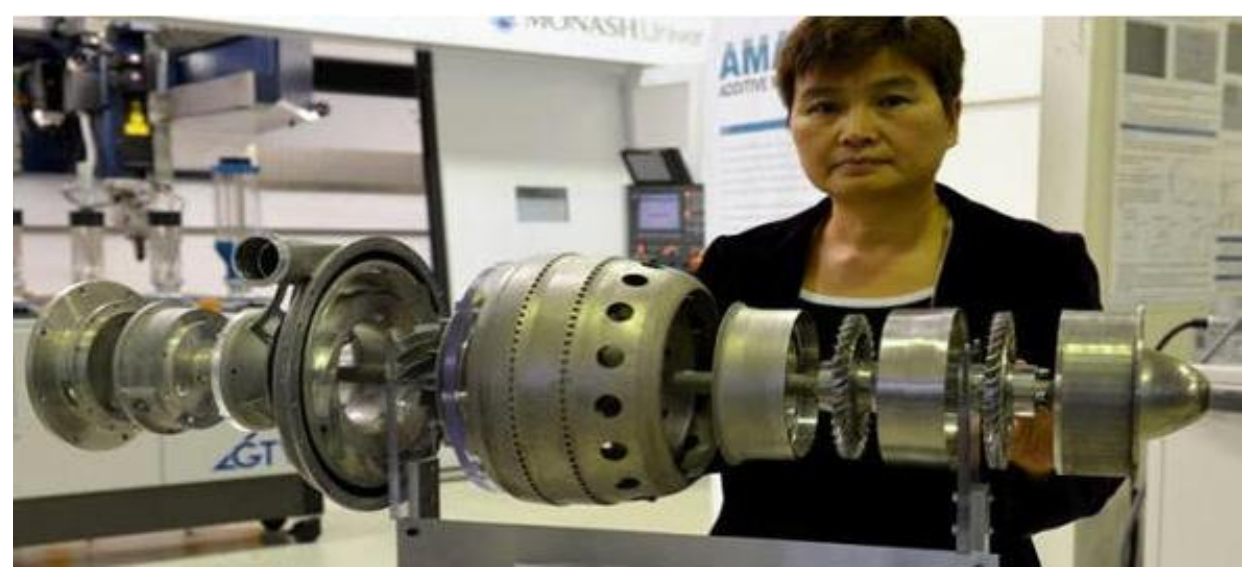

Şekil 3. 3B baskı teknolojisini kullanarak üretilen jet motoru görüntüsü [14]

3 boyutlu bask1 teknolojisinin getirdiği avantajlar ile havac1lık ve uzay sanayisinde devrim niteliğinde gelişmeler yaşanmaktadır. Türkiye' de 2023 yılı için havacılık sektörü, uzay ve savunma alanında hızlı bir değişim ve gelişim çerçevesinde büyük bir iş gücü ihtiyacı doğmuştur. Ayrıca, yüksek teknolojili yeni nesil uçaklar ile dolu havacılık sektörlerinde yeni yetenek ve kapasiteye sahip 3. Nesil silah, donamım ve teçhizat üretilmesi gerekmektedir. Bu anlamada kaliteli, nitelikli iş gücüne ihtiyaç vardır. Havacılık, uzay ve savunma alanında ihtiyaç duyduğu kişilerin yetiştirilmesinde en önemli nokta eğitimdir. Ülkemizde üniversitelerde ön lisans, lisans ve lisansüstü seviyede eğitim-öğretim faaliyetleri yapan sivil havacılık okullarının sayısı hızla artış göstermiştir. Milli Eğitim Bakanlığı tarafından ilgi artışı nedeniyle havacılık liseleri açılarak, havacılık eğitimi lise seviyesine inmiştir. Burada kuşkusuz çoğu havacılık liselerinde yeterince laboratuvar uygulama imkânı yoktur. 
Çoğunlukla eğitim-öğretim faaliyetleri teorik seviyededir. Okul ile sektör işbirliği ve koordinasyonu yeterince yapılmamaktadır [15].

Şekil 4'de 3B baskı ile imal edilmiş prototip jet motoru görülmektedir. Okullarda ilgi artışı olan havacılık, uzay ve savunma alanına ihtiyaç duyulan kaliteli, nitelikli insan kaynağının karşılanabilmesi için teknolojik uygulamaların gereklerini yerine getirilmiştir. Öğrencilerin kazandığı mesleki eğitim ile beceri ve davranışların işgücü pazarına transfer edilebilir hale dönüştürülmesi sağlanmıştır.
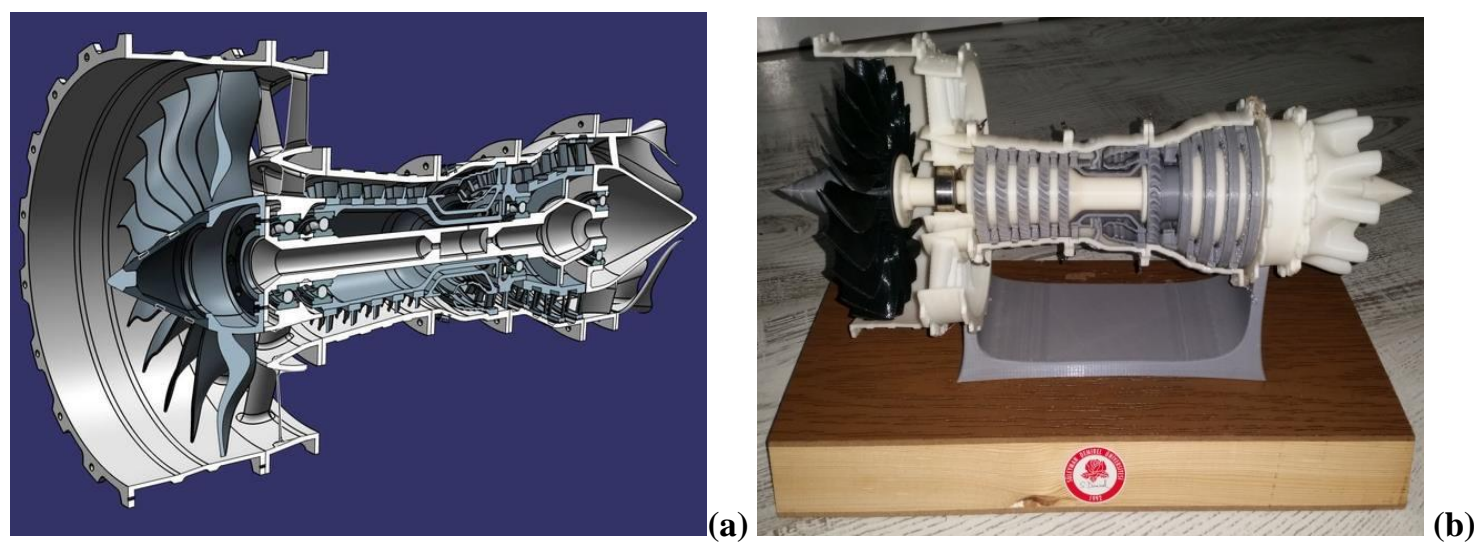

Şekil 4. Jet motorun prototip tasarım ve imalat görüntüsü; (a) jet motorun kesit alınmışgörüntüsü (b) $3 B$ baskı ile imal edilmiş jet motorun prototip görüntüsü

\section{3B Baski Teknolojisi İle Diferansiyel Dișlisis Prototip Tasarimi Ve İMALATI}

Otomobilin tahrik ve çekiç sistemini oluşturan parçalar: içten yanmalı motor, şanzıman, kavrama, taşıma elemanları aks, miller, diferansiyel ve tekerleklerdir. Bir araçtaki güç ve enerji iletim elemanları, mekanik enerjinin üretilip tekerleklere kadar iletildiği organlara verilen isimdir [16]. Diferansiyeller şaftla aks arasında güç ve enerji iletim elemanıdır. Vites kutusu (şanzıman) hız veya moment değiştirici bir dişli kutusudur. Şanzımandaki hareketin tekerleklere aktarılması için ise şaft, diferansiyel ve akslar kullanılır. Şafttan gelen hareketin torkunu veya momentini diferansiyel sayesinde arttır1lır. Diferansiyel, motor hareketinin döndürücü etkisini tekerleklere iletilmesinde kullanılan dişli kutudur. Burada her iki tekerleğe eşit olarak motor kuvveti dağıtılmaktadır. Şekil 5'de diferansiyelin yapısı ve parçaları görülmektedir. 


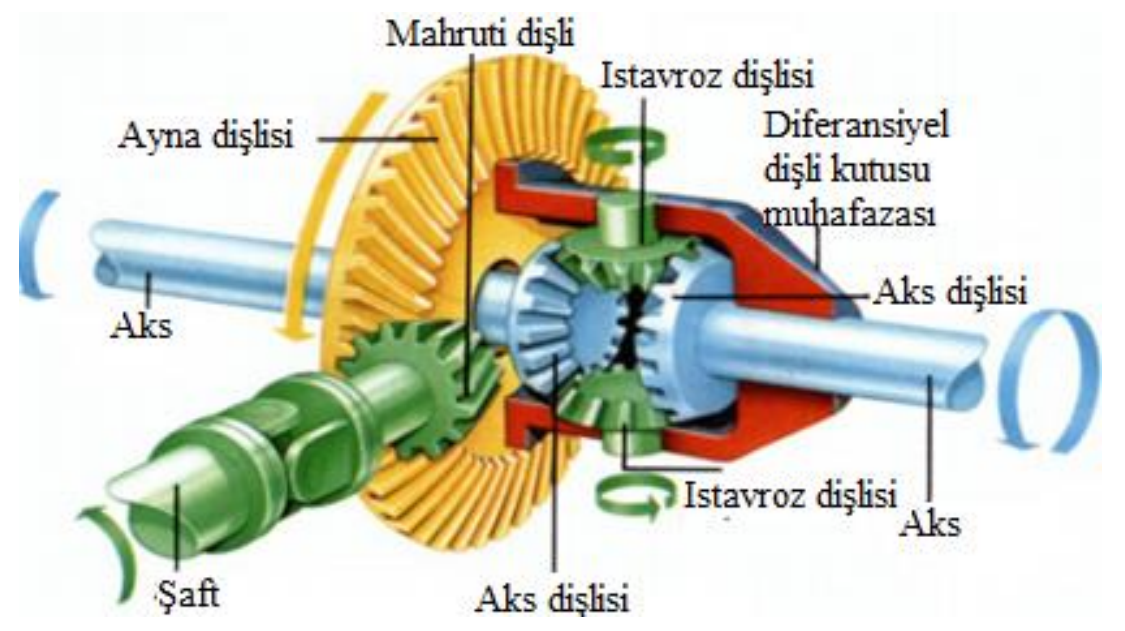

Şekil 5. Diferansiyel yapısı, parçaları ve isimleri [17]

Çalışmada Şekil 6'de gösterildiği gibi 3B baskı ile diferansiyel dişlisi prototipi imal edilmiştir. Eğitim materyali ile öğrenciler diferansiyelin teknik yapısını ayrıntılı bir şekilde incelenmiş, diferansiyelin görevleri ve yapısı hakkında bilgi sahibi olmuşlardır. Dolayısıyla mezun öğrenciler taşıtlarda şaft, diferansiyel ve akslar ile ilgili bakım ve onarım işlemlerini rahatlıkla yapabileceklerdir. Ayrıca mesleki eğitim ile beceri ve davranışların işgücü pazarına transfer edilebilir hale dönüştürülmesi sağlanmıştır [18].

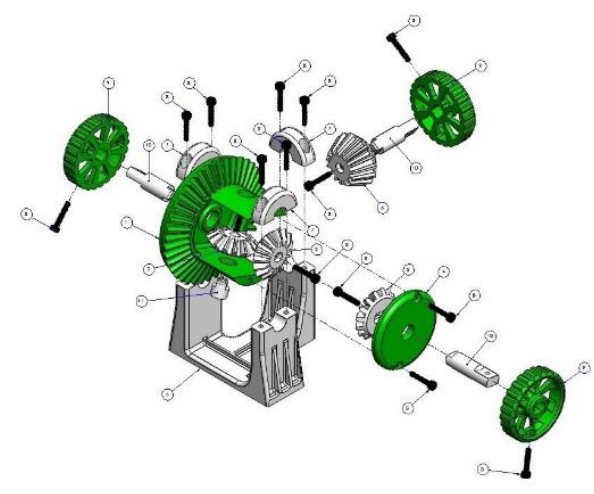

(a)

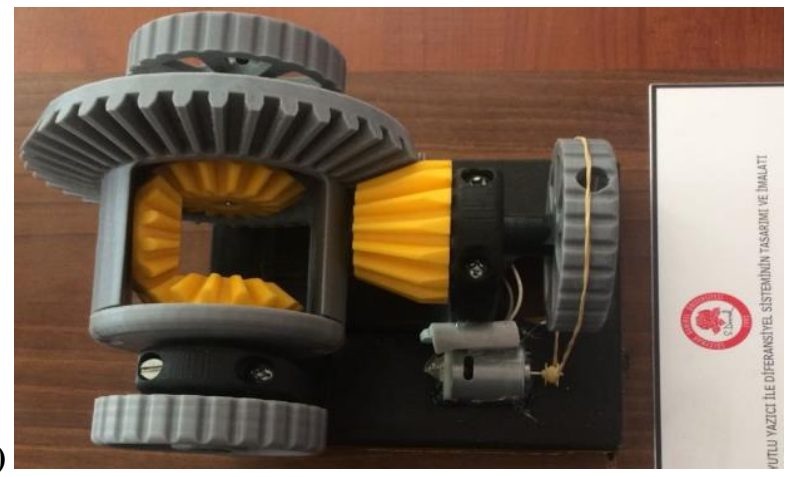

(b)

Şekil 6. Diferansiyel dişlisinin prototip tasarım ve imalat görüntüsü; a) diferansiyelin tasarım görüntüsü b) $3 B$ baskı ile imal edilmiş prototip diferansiyel dişlisinin görüntüsü

\section{3B Baski Teknolojisí İle Robot Kol Prototip Tasarimi Ve İMALATI}

Dünya literatüründe ilk defa "Robot" kelimesi 1917 y1lında Karel Capek tarafindan atılmıştır. Fakat robot kavramı anlayışı 1921 yılında ayni yazarın Rossum's Universal Robots (R.U.R.) adli tiyatro eserinde ortaya atılmıştır. Eserde robotlar Rossum ve oğlunun topluma hizmet için oluşturduğu insan görüşlü yaratıklar şeklinde bahsedilmektedir. Robot kelime olarak sıkıcı, ağır ve angarya anlamında olup, çek dilinden gelmektedir [19]. Robot kavramının gelişimi aslında geçmişten günümüze insanların her zaman ek yardımcı sistemlere ihtiyaç duymasıdır. Robotlar, otomasyon sistemleri uygulamalarında en fazla kullanılan elemanlardır. Robotik sistemler; Makine Mühendisliği, ElektrikElektronik Mühendisliği ve Bilgisayar Mühendisliğinin ortaklaşa çalışmaları sonucu ortaya çıkmıştır. 
Şekil 7'de gösterildiği gibi robot kol, programlanabilir, mekanik parçaların bütünü ya da komplex bir robotun bir parçası olarak nitelendirebilir [18]. Günümüzde robotik kollar endüstrinin ayrılmaz bir parçası haline gelmiştir. İnsan gücünü en aza indirerek, hata payı oranını azaltıp üretim miktarını üst seviyelere getirerek, günümüz teknolojisine önemli derecede katkı sağlamaktadır. Robotlar temel olarak kapsam ve yeteneklerine göre kartezyen, silindirik, polar, revolüt olarak yapısal sinıflandirılabilirler.

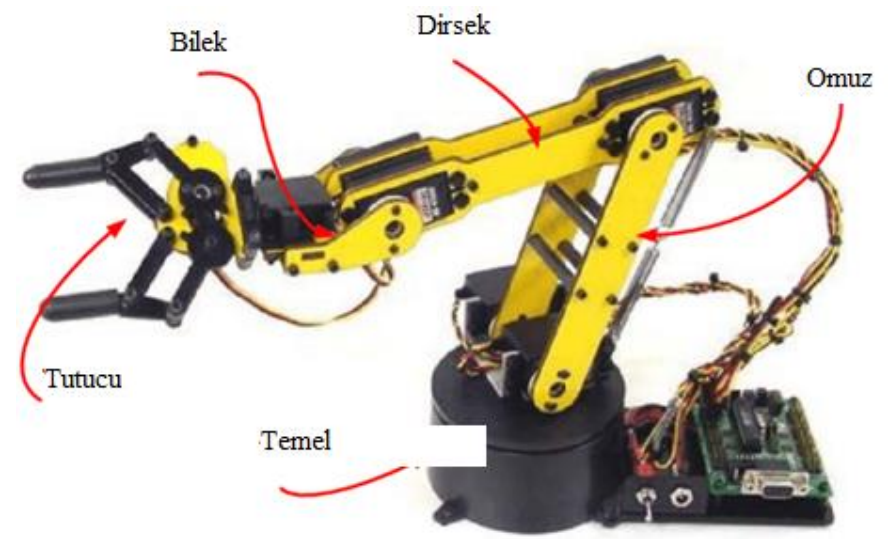

Şekil 7. Lynx6 robot kol görüntüsü [20]

Ülkemizde de robot kullanımı yaklaşık değerler otomotiv sektöründe yoğun olup, bu değer \%32'dir. Otomotiv yan sanayisinde ise bu oran \%22'dir. İki sektör birlikte dikkate alındığında ülkemizdeki robotların yarıdan fazlasını otomotiv ve alt sanayilerde kullandığı görülmektedir. Cam ve seramik sektöründe $\% 23$, Beyaz eşya $\% 13$ ve diğer sektörlerde $\% 11$ şeklindedir.

Çalışmada Şekil 8'da gösterildiği gibi 3B baskı ile robot kol prototip imal edilmiştir. Robot kol bilgisayar yardımıyla insan kol yapısına benzer fonksiyona sahip ve esnek bir yapıyı oluşturmaktadır. Robot kol prototip uygulama yenilikçi eğitim ile okul müfredatında yer alması ve öğrencilerin motivasyonu artırması açısından çok önemli hale gelmiştir [21,22].

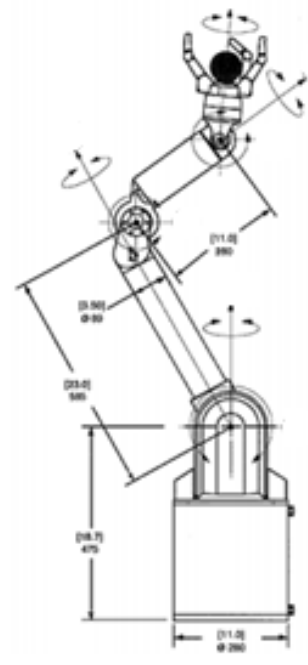

(a)

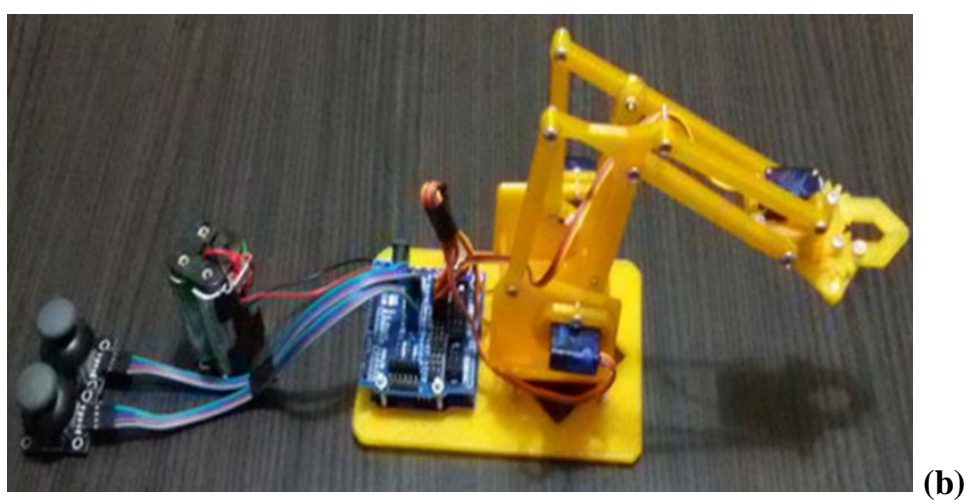

Şekil 8. Robot kol prototip tasarım ve imalat görüntüsü; a) robot kol tasarım görüntüsü b) 3 B baskn ile imal edilmiş prototip robot kol görüntüsü 


\section{YÖNTEM}

\section{A. ÇALIŞMA DESENI}

Çalışma Süleyman Demirel Üniversitesi Senirkent Meslek Yüksekokulu'nda bulunan teknik programda okuyan öğrencilerin 3B baskı teknolojileri hakkında bilgilendirme ve kullanma süreci ile ilgili deneyimlerini incelenecektir. Burada nitel araştırma desenlerinden fenomenolojik (görüngübilimsel) desen kullanılmıştır. Fenomenolojik desen, bireylerin yaşanmış deneyimlerini öğrenmeye yönelik bir çabadır[23]. Çalışmada, ön lisans öğrencilerin görüşleri doğrultusunda 3B baskı teknolojisi kullanımı deneyimleri yorumlanarak yansıtılması amaçlandığından fenomenolojik bir desen tercih edilmiştir.

\section{B. ÇALIŞMA GRUBU}

Katılımcılar amaçsal örnekleme yöntemlerinden ölçüt örnekleme yöntemiyle seçilmiş, bu doğrultuda elektrik bölümü ön lisans programında öğrenim gören son sınıf öğrencileri seçilmiştir. Bu ölçütün belirlenmesinin nedeni, okudukları programla ilgili deneyimlerinin fazla olduğu düşüncesidir[24]. 2017-2018 eğitim y1lında Süleyman Demirel Üniversitesi Senirkent Meslek Yüksekokulu elektrik bölümü son sınıf 6 erkek öğrenci ile yarı - yapılandırılmış görüşme tekniği ile veriler toplanmıştır.

\section{VERI TOPLAMA SÜRECI}

Fenomenolojik araştırmada deneyimin altında yatan temel yapıyı ve gerçekliği elde etmek için görüşme, öncelikli veri toplama yöntemidir[25]. Çalışma verileri, önlisans öğrencileri ile bireysel olarak yüz yüze yapılan yarı-yapılandırılmış görüşmeler yoluyla toplanmıştır. Yarı- yapılandırılmış görüşme tekniği sahip olduğu belirli düzeydeki standartlığ ve esnekliği nedeniyle araştırmalarda yaygın olarak kullanılmaktadır[26]. Bu amaçla bir görüşme formu geliştirilmiştir. Çalışmada kullanılan görüşme formunun geliştirilmesi aşamasında, 1 eğitim bilimi ve 2 elektrik enerji bilimi alan uzmanlarının görüşleri alınmış, görüş ve önerileri doğrultusunda gerekli düzeltmeler yapılmıştır. Uzman görüş ve önerileri doğrultusunda düzenlemeler yapılmıştır. Görüşme formunda 3B bask1 teknolojileri hakkında bilgilendirme ve kullanma süreci ile ilgili deneyimlerini incelemeye yönelik sorular yer almıştır. Öğrenciler ile yüz yüze görüşmeler yaklaşık 20-30 dakika sürmüştür. Görüşmeler kayıt cihazı ile kaydedilerek yazı dökümü yapılmıştır. Verilerin analizinde; tümevarımsal analiz yaklaşımıyla içerik analizine tabi tutularak temalara ulaşılmıştır. Daha sonra oluşturulan temaların doğruluğunu test etme amaciyla tümdengelimsel analiz yaklaşımıyla temalar netleştirilmiştir[27].

\section{D. ÇALISSMANIN GEÇERLI $\breve{G} \dot{I} V E$ GÜVENIRLI $\breve{G} \dot{I}$}

Guba ve Lincoln nitel araştırmalarda geçerlik-güvenilirlik konusunda güvenilirlik olması için bazı ölçütler belirlemiştir[25]. İnanılırlığ artırmak için kullanılan pek çok yöntem vardır. Çalışmada katılımcıların 3B baskı teknolojileri hakkında bilgilendirme ve kullanma süreci ile ilgili deneyimlerini derinlemesine anlayış geliştirmek amacıyla uzun süreli etkileşim sağlanmıştır. Bununla birlikte araştırma deseninden toplanan verilere, ulaşılan tema ve sonuçların yazımına kadar olan süreçler objektif biçimde raporlanmıştır. Çalışmanın tutarlılığını artırmak amacıyla, araştırma deseninden toplanan verilere, ulaşılan tema ve sonuçların yazımına kadar olan süreçlerin incelenmesi için akran değerlendirilmesi yoluna başvurulmuştur. 


\section{E. ÇALIŞMANIN SINIRLIKLARI}

Çalışmada bulguları etkileyecek bir takım kısıtlamalar olabilir. Bunlar,

- Çalışma tek bir üniversite ile sinırlı tutulmuştur.

- Çalışmada veri toplama sürecinde çeşitleme yapılamamıştır.

- Çalışmada ölçüt örneklem yöntemiyle katılımcılar seçildiği için genellenebilirliğini sinırlandirmaktadır.

\section{BULGULAR}

Bulgular, ön lisans öğrencilerden edinilen veriler 1şığında iki ayrı tema halinde kategorize edilmiştir. Temalar; (1) 3B baskı teknolojileri hakkında bilgi sahibi olma ve kullanma, (2) Öğrenme - öğretme süreci yaşantılar şeklindedir. Çalışmanın bulgularına ilişkin temalara ait ayrıntılı bilgiler katılımcıların görüşlerinden alıntılar aşağıda sunulmuştur.

\section{A. TEMA-1: 3B BASKI TEKNOLOJILERI HAKKINDA BILGI SAHIBİ OLMA VE KULLANMA}

Öğrencilerin görüşleri çerçevesinde; elektrik bölümü önlisans programı yapı itibariyle temel teknik bilim bir görünüm sergilemekte ve buna bağlı olarak ön lisans öğrencileri yeni bir teknoloji olarak görülen ve kullanımı yaygınlaşan 3B baskı teknolojisini bilmediği görüşündedirler. Bu durumun göstergesi olarak, eğitim ve eğitim alt alanlarında 3B baskı teknolojisinin çok fazla derslerde yer almadığı, yine aynı şekilde doğrudan eğitim alanında bazı derslerin müfredat içerisinde zorunlu olarak alınması gerektiğini ifade etmektedirler. Söz konusu bu bulgulara ilişkin katılımcı görüşleri aşağıdaki gibidir:

K6: “3B yazıcıları ilk kez Senirkent MYO’da gördük. Robot kol parçalarını basabileceğimiz bir yazıcı kullandık ve öğrendik. Bunları araştırdık. Ben uygulama imkânımız olmayan deneylerin 3B baskı teknolojisi ile çıktısı alınarak, 3B düşünebilme kabiliyeti geliştirdiğime inanıyorum. Bazı derslerin müfredat içerisinde zorunlu olarak alınması gerektiğini düşünüyorum.”

K2: "3B yazıcı ile diferansiyel dişli prototip imalatı gerçekleştirdik. Hepsini adım adım yaptık. Biz bu çalışmayı sadece kendi bölümüzü için yapmadık, diğer makine ve makine resim konstrüksiyon bölümleri için de basabiliriz. Bu sayede okulda arkadaşlarımıza yardımda bulunuyoruz."

K5: "3B baskı ile jet motoru prototip imal ettik. Jet motoruna kompresör ile hava göndererek meydana gelen etki-tepki kuvvetlerini görmüş olduk. Bu sayede Jet motorun nasıl çalıştığını anlatılırken sadece dinleyen değil, soru sorma ve araştırma imkânı elde ettik.”

\section{B. TEMA-2: $\ddot{O} \breve{G R E N M E ~-~ O ̈ G ̆ R E T M E ~ S U ̈ R E C I ~ Y A S ̧ A N T I L A R ~}$}

Endüstrinin ihtiyaç duyduğu nitelikli, kaliteli ara kademe tekniker adayların ön lisans programının uygulayıcısı konumunda olan öğretim görevlilerinin, derslerde önceleri sözel ve sunuda şekillerle ifade edilen anlatım çok zor olduğu ve 3B baskı teknolojileri sayesinde hatırlama ve anlama kolaylaştığ görüşündedirler. 
K4: "Ben öğretim görevlisi olsam, "3B yazıc1 sayesinde teorik derslerde konunun anlaşılması açısından verilen örneklerin küçük modelleri baskısı alırım. Bu sayede derse olan ilgiyi ve motivasyonu arttırmış olurum.”

K1: "Kendi okulumuzda laboratuvarların yetersiz ve uygulamaları az olmasından dolay1 3B bask1 ile mesleki eğitimin iyileştirildiğini düşünüyorum"

K3: "1. Sınıfta elde ettiğimiz bilgileri sayesinde tasarladığımız projeleri 3B baskı ile hayata geçirme olanağına sahip olduk. Derslerin akılda etkili ve kalıcı sonuçlar vermesi adına önemli bir yeniliktir."

\section{SONUÇLAR}

Süleyman Demirel Üniversitesi Senirkent Meslek Yüksekokulu'nda bulunan teknik programda okuyan öğrencilerin 3B bask1 teknolojisi yenilikçi eğitim uygulaması ile "Dijital Dönüşüm" devriminin gerçekleştirmesi amaçlanan bu çalışma ile bulunan sonuçlar şu şekilde özetlenmiştir:

- Öğrenciler 3B baskı teknolojisinin kullanımı ile birlikte öğrenci görüş ve algılarına göre 3B düşünebilme kabiliyeti elde ettiklerini belirtmişlerdir. Bu bulgudan yola çıkarak öğrencilerin tasarladıkları bir parçanın 3B baskı teknolojisinin ara yüzüne kolaylıkla erişip imal etme becerileri gelişmiştir. Ayrıca öğrencilerin analitik düşünme becerilerin geliştirilmesi ile proje tabanlı öğrenime aşamalarına geçilmiştir. Öğrencilerin derslerden elde ettikleri bilgiler yardımıyla tasarladıkları projeleri 3B baskı ile hayata geçirme olanağına sahip olmuşlardır.

- 3B baskı sayesinde, öğrenciler tarafindan anlaşılması güç olan konuların anlatılması kolaylaştııılmıştır. Ayrıca interaktif sınıf aktivitesi sağlanmıştır.

- Teorik derslerde konunun anlaşılması açısından verilen örneklerin küçük modelleri baskısı alınarak, öğrencilerin ilgisi ve motivasyonu artırılmıştır.

- MYO'larda laboratuvarların yetersiz ve uygulamaları az olmasından dolayı 3B bask1 ile mesleki eğitimin iyileştirilmesi sağlanabilir.

- Sanayiye nitelikli teknik eleman yetiştiren meslek yüksekokullarında 3B baskı teknolojisinin eğitiminin verilebilir.

- 3B bask1 teknolojisi sektörü katma değer ve verimliliğini arttıran çözümleri ile KOBİ’lerin rekabet gücünün geliştirilmesinde ve sanayide dijitalleşme oranının artırılmasında kritik öneme sahip olmasından dolayı geleceğin teknolojisi olarak ifade edilmektedir. 


\section{KAYNAKLAR}

[1] M. E. B. "Mesleki ve Teknik Eğitim Öğretmeni Yetiştirme", Öğretmen Yetiştirmede Koordinasyon ve İşbirliği Toplantısı, Milli Eğitim Basımevi, Ankara, 1996.

[2] A. Özsoy, "Teknik Eğitim Fakültelerin Yeniden Yapılandırılması”, Politeknik Dergisi, c. 4, s. 2, ss. 61-73, 2001.

[3] H.C. Bayrakçı ve K. Özsoy, "Meslek Yüksekokulları Teknik Programlarındaki Öğrencilerin Okul ve Mesleklerinden Beklentileri”, 4. Ulusal Meslek Yüksekokulları Sempozyumu, İzmir, Türkiye, 2007, ss. 536-540.

[4] J. Giannatsis and V. Dedoussis, "Additive Fabrication Technologies Applied to Medicine and Health Care: A Review", International Journal Addive Manufacture Technologies, vol. 40, no.1-2, pp. 116-127, 2009.

[5] Custompartnet, Additive Fabrication, (2017, 24 Şubat). [Online]. Erişim: http://www.custompartnet.com/wu/additive-fabrication

[6] İ. Çelik, F. Karakoç, M. C. Çakır ve A. Duysak, "Hızlı Prototipleme Teknolojileri ve Uygulama Alanları", Dumlupınar Üniversitesi, Fen Bilimleri Enstitüsü Dergisi, c. 13, s. 31, ss.53-69, 2013.

[7] B. Duman, "Seçmeli Lazer Ergitme İle Metal Parça İmalatında Takım Yolu Belirleme Ve Eniyileme", Doktora Tezi, Makine Mühendisliği Bölümü, Süleyman Demirel Üniversitesi, Isparta, Türkiye, 2016.

[8] Turkcadcam.net, Oto İnşaa Yöntemleri, (2017, 24 Şubat). [Online]. Erişim: http://www.turkcadcam.net/rapor/autofab/

[9] Custompartnet, Selective Laser Sintering, (2017, 12 March). [Online]. Available: http://www.custompartnet.com/wu/selective-laser-sintering

[10] Wikipedia, Jet Motor, (2018, 27 Ocak). [Online]. Erişim: https://tr.wikipedia.org/wiki/Jet_motoru

[11] T. Giampaolo, The Gas Turbine Handbook: Principles And Practices, 2nd. ed., New York, USA: The Fairmont Press, 2003.

[12] B. Gunston and P. Stephens, The Development of Jet and Turbine Aero Engines, Sparkford, USA: Patrick Stephens Limited, 1997.

[13] Mühendisbeyinler, Gaz Türbinli Jet Motorlar, (2018, 27 Ocak). [Online]. Erişim: https://www.muhendisbeyinler.net/gaz-turbinli-motorlar-jet-motorlar/

[14] Hürriyet Teknoloji , (2018, 31 Ocak ). [Online]. Erişim: http://www.hurriyet.com.tr/ucboyutlu-yazicida-ilk-kez-jet-motoru-yapildi-28386947 
[15] S. Uslu, “Türkiye' de Akademik Havacılık Eğitiminin Tarihi, Mevcut Durumu ve Geleceği”, III. Ulusal Havacılık Teknolojisi ve Uygulamaları Kongresi, Eskişehir, Türkiye, 2015.

[16] R.N Tuncay, M. Tırıs, , F. Akgün, vd., “TÜBİTAK'da İleri Enerji Teknolojileri”, yayınlanmış teknik rapor.

[17] MEGEP Ders Notları , (22 Şubat 2018). [Online]. Erişim: http://www.megep.meb.gov.tr/mte_program_modul/moduller_pdf/\%C5\%9Eaft,\%20Diferansiyel\%20 Ve\%20Akslar.pdf.

[18] Functional Differential Gear System, (2018, 22 February). [Online]. Available: https://www.thingiverse.com/thing:12896

[19] Robotların Tarihçesi, Boğaziçi Üniversitesi, Robot Sitesi, (04 Mart 2018). [Online]. Erişim: http://robot.cmpe.boun.edu.tr/593/

[20] Lynxmotion, Lynx6 robot arm, (2018, 4 Mart ). [Online]. Erişim: http://www.lynxmotion.com

[21] Robot kol tasarımı, (2018, 4 Mart). [Online]. Erişim: https://webdedecanavarim.files.wordpress.com/2013/04/robot_kol_tasarimi.pdf

[22] Yapalım, Robot kol, (2018, 4 Mart). [Online]. Erişim: www.yapalim.net/2015/07/04/robotkol-projesi/

[23] K. Karataş, "Sınıf Öğretmenliği Lisans Programının Sınıf Öğretmeni Adaylarının Kültürel Değerlerine Duyarlı Olması Açısından İncelenmesi”, 4. Uluslararası Eğitim Programları ve Öğretim Kongresi, Antalya, Türkiye, 2016.

[24] J. Creswell, Nitel Araştırma Yöntemleri, Siyasal Bookstore, Ankara, 2015.

[25] S. B. Merriam, Nitel Araştırma: Desen ve Uygulama Için Bir Rehber, Ankara, Türkiye: Nobel Akademik Yayınc1lı, 2013.

[26] A. Türnüklü, "Eğitimbilim Araştırmalarında Etkin Olarak Kullanılabilecek Nitel Bir Araştırma Tekniği: Görüşme”, Kuram ve Uygulamada Ĕ̆itim Yönetimi Dergisi, c. 24, ss. 543-559, 2000.

[27] Q. M. Patton, Nitel Araştırma ve Değerlendirme Yöntemleri, Ankara, Türkiye: Pegem Yayınc1lik 2014. 